\title{
LA CIUDAD ANTE EL CONTAGIO: MEDIDAS POLÍTICAS Y ADMINISTRATIVAS DICTADAS EN LA EPIDEMIA DE FIEBRE AMARILLA DE 1804 EN ALICANTE
}

\author{
Mercedes Pascual Artiaga \\ Depto. de Salud Pública, Historia de la Ciencia y Ginecologia \\ Universidad Miguel Hernández. Alicante
}

\section{RESUMEN}

Desde 1800 la fiebre amarilla comenzó a producir en la península ibérica episodios epidémicos. En el artículo se presentan y analizan las medidas que instauraron las diversas Juntas de Sanidad implicadas en el control del brote epidémico que afectó a la ciudad de Alicante en 1804. El estudio del caso alicantino ha permitido contextualizar dicho análisis en el marco de lo sucedido en otras localidades durante ésta y otras epidemias. Se constata la coexistencia de medidas tradicionales de prevención y de nuevas medidas. Las medidas administrativas y sanitarias se centraron en asegurar el aislamiento de la población afectada para evitar la extensión de la enfermedad y prolongarlo el mayor tiempo posible, como una garantía para las localidades vecinas.

PALABRAS CLAVE: fiebre anarilla, política sanitaria, Alicante, siglo XIX.

\section{SUMMARY}

Since 1800 the yellow fever started producing epidemic incidents in the Iberian Peninsula. In this article the measures that were established by the different sanitary assemblies implied in the control of the epidemic outbreak that affected the city of Alicante in 1804 are shown and analysed. The study of this case in Alicante has allowed to put in context this analysis in the framework of what happened in other places during this and other epidemies. It is proved the coexistence of traditional measures of prevention and of new ones. The political and sanitary speech focused on assuring the isolation of the population affected in order to avoid the spreading of this disease and to extend it as long as possible, as a quarantee for the surrounding cities.

KEY WORDS: yellow fever, health policy, Alicante, $19^{\text {th }}$ century. 


\section{INTRODUCCIÓN}

El miedo al contagio, y más concretamente a la importación de la fiebre amarilla, llevó a la ciudad de Alicante, al igual que otras, a adoptar medidas preventivas desde $1800^{1}$. Muchas de estas precauciones se dirigían contra el contrabando, sobre todo de tabaco, al que se responsabilizaba a menudo de ser la causa del inicio de las epidemias. Se ejercía un riguroso control de los sectores más marginados socioeconómica y culturalmente ante la más ligera sospecha de cualquier enfermedad contagiosa ${ }^{2}$. Se incrementaron las precauciones en los puertos, intercambiándose la información relativa a la salud de mercancías, personas y equipajes de las embarcaciones por distintos conductos de unas ciudades portuarias a otras. Era general la orden de pasar por vinagre la correspondencia procedente de Andalucía, «en los propios términos que se executava en el tiempo de la desgraciada epidemia de Cádiz»³.

En este contexto, muchas de las medidas adoptadas estaban informadas por la medicina del momento. Sobre la influencia de la ciencia médica en la aplicación de medidas de carácter preventivo se han desarrollado algunas polémicas historiográficas. Destaca, en este sentido, la contraposición entre las tesis defendidas por Ackernecht y por Margaret Pelling ${ }^{4}$, sobre las relaciones existentes entre la evolución de la epidemiología y de las teorías médicas y la influencia en la misma de diferentes factores socioeconómicos. En cualquier caso, parece evidente que la opinión médica adquirió una importancia creciente y asumió un papel cada vez mayor en la sociedad como asesora de las autoridades gubernativas en la elección de las medidas preventivas. En ocasiones parece que las autoridades de fuera del municipio hacen un uso

\footnotetext{
${ }^{1}$ Nos referimos fundamentalmente a la irrupción y extensión de la fiebre amarilla que en 1800 afectó a Cádiz, en 1803 se extendió por Andalucía fundamentalmente a Málaga y en 1804 abarcó una extensa franja del litoral mediterráneo llegando a Alicante.

2 Archivo Municipal de Alicante (desde ahora AMA ). Sanidad. Fiebre amarilla, sig. 182. Edicto de José Betegón, Alicante 17 de junio de 1805. Prevenciones a tomar ante la proximidad del verano con motivo de un posible rebrote de fiebre amarilla: «Los ociosos, vagos y mal entretenidos serán castigados con arreglo a la Real Ordenanza de leva de 7 de mayo de 1775 y órdenes posteriores y del mismo modo serán tratados los mendigos voluntarios y robustos; (y) los inválidos y verdaderamente impedidos saldrán inmediatamente de la ciudad, sin que se permita entre alguno de nuevo en ella».

3 AMA. Sanidad, leg. 1, núm. 1 bis, año 1800; leg. 1, núm. 4 bis, año 1803.

4 ACKERKNECHT, E. H. (1948), «Anticontagionism between 1821 and 1867», Bulletin of the History of Medicine, 22, 562-593; PELLING, M. (1978), Cholera, Fever and English Medicine, Oxford Univ. Press. El primero opina que las medidas preventivas quedaron condicionadas a lo largo del tiempo por las repercusiones socioeconómicas de las mismas, es decir, la relación entre la medicina y la sociedad modeló la evolución de la epidemiología. Por el contrario, M. Pelling rechaza la influencia de la epidemiología por factores extracientíficos y afirma que el desarrollo y la práctica epidemiológica de una época se configuró, en el contexto inglés, a partir de los propios supuestos internos de la medicina del siglo XIX. Citados ambos en RODRIGUEZ OCAÑA, E. (1981), «La dependencia social de un comportamiento científico: Los médicos españoles y el cólera de 1833-35», Dynamis, 1, 101-130 (especialmente pp. 101-103).
} 
arbitrario de determinadas prevenciones para ocultar otros intereses, como parece ocurrir con las fumigaciones obligadas por el gobierno central que debían realizarse como requisito previo para que un territorio fuera declarado sano tras una epidemia y poder reanudar sus actividades. Analizaremos las diferentes medidas sanitariopolíticas que se adoptaron en Alicante frente a la fiebre amarilla y las posibles razones que las justificaban ${ }^{5}$.

\section{LA CIUDAD DE ALICANTE EN 1804}

Para entender la conmoción que causaban este tipo de enfermedades epidémicas en una población parece obligado resumir las condiciones físicas, sociales, económicas y asistenciales que reunía la ciudad. En 1803 Alicante se encontraba en expansión, con más casas extramuros. Al ser plaza fuerte, se hallaba protegida por murallas en cuyo interior las casas se extendían —desde los puntos más altos hacia la parte baja- formando calles muy estrechas ${ }^{6}$. Una pequeña parte de la población habitaba intramuros mientras que la mayor densidad demográfica la alcanzaban las zonas extramuros ${ }^{7}$.

La localidad se dividía en seis zonas o cuarteles correspondientes al centro de la ciudad, barrio de Santa Cruz, barrio de San Roque, la Villavieja y el Raval Roig, el arrabal de San Antón y el de San Francisco ${ }^{8}$. El barrio de San Antón era el que albergaba el mayor porcentaje de población, siendo uno de los más deprimidos, seguido por el de San Francisco, donde abundaban los almacenes de los comerciantes que traficaban a través del puerto. La escasez de viviendas, en relación con el número de

5 Este artículo ha sido elaborado con los materiales recopilados en la elaboración de mi memoria de investigación titulada Hambre, enfermedad y muerte. La sociedad alicantina frente a la epidemia de fiebre amarila de 1804, que presenté en la Universidad de Alicante en marzo de 1998.

6 VIRAVENS y PASTOR, R. (1876), Crónica de la muy Ilustre y siempre fiel ciudad de Alicante, Alicante. (Ed. facsímil, 1976, ed. Agatángelo Soler, Alicante), pp. 121/122.; RAMOS, V. (1971), Historia de la provincia de Alicante y de su capital, T.1, Diputación Provincial, Alicante, pp. 13/14.

7 En 1801 se rogaba a Godoy que se permitiera la construcción fuera de las murallas, a causa de la aglomeración urbana que existía, la falta de viviendas y la abundancia de la población. vid: GIMÉNEZ LÓPEZ, E. (1981), Alicante en el siglo XVIII. Economía de una ciudad portuaria en el antiguo régimen, Institució Alfons el Magnànim / Diputació de València, Valencia, pp. 56-61; Sobre las características de la ciudad en los siglos XVIII y XIX y su evolución hasta la primera mitad del siglo XIX, es de considerable interés: CALDUCH CERVERA, J. (1990), La ciudad nueva. La construcción de la ciudad de Alacant en la primera mitad del siglo XIX, Patronato Municipal del Quinto Centenario de la ciudad de Alicante, Alicante; También aporta datos sobre la situación urbana a principios del siglo XIX, RAMOS HIDALGO, A. (1984), Evolución urbana de Alicante, Instituto Juan Gil-Albert, Alicante, pp.197-199.

8 Sobre las características de los diferentes distritos de la ciudad de Alicante vid TONDA MONLLOR, E. (1995), La ciudad de la transición: población, economía y propiedad en Alicante durante el siglo XIX Instituto Juan Gil-Albert, Alicante (especialmente pp. 55- 64). 
habitantes, era padecida sobre todo por los más pobres. En 1803 se denunciaba: «...en muchas de las casas, por no permitirse la construcción, en virtud de órdenes reales, en los arrabales de afuera del muro se reducen a morar dos y más familias y en el casco de la ciudad se verifica lo mismo»?.

Las diferentes clases sociales ejercían un peso social y un poder decisorio diferente. La nobleza local, que fue muy importante durante todo el siglo XVIII, controlaba el poder político mediante el gobierno municipal. El grupo de los negociantes y mercaderes gozaba de claro predominio económico por la importancia del comercio marítimo para la ciudad ${ }^{10}$. La mayoría de la población de Alicante disfrutaba de un nivel de ingresos muy bajo.

Entre 1802 y 1804 una grave crisis agrícola y de subsistencias —de la que no se libró nuestra ciudad— asoló todo el país ${ }^{11}$ afectando a los jornaleros, labradores y en general a todas las personas que trabajaban o dependían del jornal para subsistir ${ }^{12}$. En ese período el trigo alcanzó elevados precios dificultando su adquisición por las clases menos pudientes ${ }^{13}$. La actividad de Alicante —eminentemente comercial— con-

9 AMA. Interrogatorio, año 1803, arm.5, lib. 99, f. 84

10 GIMÉNEZ LÓPEZ, E. (1981), pp.185-208. Describe la composición social y profesional, así como los niveles de renta de los habitantes de la ciudad de Alicante y el poder que ejercían en la misma.; Sobre la estructura profesional a principios del XIX, vid RAMOS HIDALGO, A. (1984), pp. 185-188, $243-245$.

11 AMA. Libro de cabildos de 1804. En sesión de 24 de mayo de 1804, el síndico personero informaba de la escasez de trigo y aceite, pues los «tragineros» consideraban insuficiente el precio fijado y se retiraban sin hacer su plaza. Sobre la crisis de subsistencias, 1802-1804, cf. ANES ÁlVAREZ, G. (1970), Las crisis agrarias en la España moderna, Madrid y PÉREZ MOREDA, V. (1984), «Consum deficitari, fam i crisis demogràfiques a l'Espanya dels segles XVI-XIX», Estudis d'Història Agrària, 5, 7-24. Diversos documentos de la época hacen referencia al problema de la crisis agricola y de subsistencias entre ellos: AMA. Expedientes y veredas, arm.15, lib.35, ff. 311/312. Desde Agost el 31 de mayo de 1804 se informaba que apenas existían granos y que sus dueños los necesitaban para sostener a sus familias. Las cosechas próximas se consideraban perdidas por la escasez de aguas, semillas malas y «muchas nieblas». AMA. Expedientes y veredas, arm.15, lib.35. El 23 de marzo de 1804, Manuel Antonio Santisteban comunicaba al corregidor de Alicante que los comisarios y el procurador general de la Real Cabaña habían presentado denuncia al consejo, por sufrir en los viajes infinitas molestias y vejaciones debido a que los pueblos estaban sumidos en la mayor miseria. Les insultaban por la noche, robaban sus alimentos e incluso parte de los géneros que conducían. No se les dejaba apacentar en casi ningún pueblo y por ello pedían protección a los justicias.

12 AMA. Expedientes y veredas, arm. 15, lib. 34. El Consejo Supremo, el 7 de octubre de 1803, ordenaba al corregidor de la ciudad de Alicante que promovieran obras públicas para emplear a los pobres, ya que «la falta de ocupación de los muchos trabajadores y jornaleros que la esterilidad del presente año ha de dexar abandonados a la miseria sin poder adquirir el sustento para sí y sus familias (...) Estas consideraciones (...) han convencido al consejo de la necesidad de tomar providencias eficaces y activas para el mantenimiento del pobre jornalero, en la temporada rigorosa del invierno, y prevenir el crimen, la hambre, las enfermedades y demás resultas perniciosas que de ello se originan».

13 AMA. Expedientes y veredas, arm.15, lib.34. Cayetano de Urbina el 20 de octubre de 1803 se dirigía al corregidor de Alicante y le comunicaba que el consejo, enterado del «asombroso precio que han 
dicionó que el objetivo prioritario de la explotación agraria no fuera el abastecer a la población de los productos de primera necesidad, que se adquirían a través del tráfico portuario ${ }^{14}$. Como consecuencia, la densidad demográfica de Alicante era mucho más elevada de lo que sus propios recursos podían permitir.

La infraestructura higiénico-sanitaria a principios del siglo XIX, era por otra parte, muy deficiente. En los documentos consultados en el archivo municipal hay continuas referencias sobre su «deplorable estado», necesidad de policía sanitaria y diversas mejoras. La Real Cédula de 15 de mayo de 1788 ordenaba a los corregidores y alcaldes mayores que velasen por la limpieza de las calles, que se empedrasen las mismas, se procurase ensancharlas y se realizasen plazuelas cuando el derribo de las casas existentes lo permitiera. El aseo y la limpieza se consideraban la base de la salubridad ${ }^{15}$.

Los conductos de las aguas y de las inmundicias eran defectuosos. El abastecimiento de agua se realizaba desde el depósito de la Casa Blanca a la ciudad, a través de un conducto subterráneo que se hallaba muy deteriorado y que en algunos tramos se cruzaba con las «acequias de la inmundia», lo que había provocado en algunas ocasiones la mezcla de ambas ${ }^{16}$. En las calles se acumulaban los animales muertos, andrajos, despojos de vasijas y otros desperdicios, que habitualmente eran retirados por los labradores que recogían el estiércol de la población ${ }^{17}$.

El matadero - situado en la puerta de Elche en el centro de la ciudad—originaba numerosas críticas. En julio de 1804 en una sesión del cabildo municipal se denunciaba el fuerte hedor que despedía, como una amenaza a la salud pública, y el peligro que constituía el traslado de las reses vacunas al mismo que ya había ocasionado algún accidente por lo que se proponía su traslado a otro lugar más a propósito ${ }^{18}$.

La cárcel se hallaba en el centro de la ciudad y en 1804 su alcaide temía que se originara alguna enfermedad al estar «embarazadísima», por haber incluido a los

tomado los granos y a fin de concurrir con las providencias que se estimen correspondientes para contenerle», solicitaba noticias sobre las cantidades de granos de todas las especies que se recogieran en los pueblos durante el mes de septiembre de ese año 1803 y de los precios que se cobraban.

14 AMA. Expedientes y veredas, arm.15, lib.35. En respuesta al interrogatorio sobre producciones nacionales del reino, se informaba que el pueblo de Alicante se abastecía de granos por el mar.

15 AMA. Expedientes y veredas, arm.15, lib.36, año 1805, ff. 301, 301v.

16 AMA. Interrogatorios, año 1803 , f. 88 v.

17 AMA. Libro de cabildos de 1804, ff. 109 v, 110. Sesión del 2 de julio de 1804: se acordó pagar cincuenta pesos anuales a Gregorio Giner y su hijo para que retiraran de las calles de la ciudad los perros y animales muertos. Ff. 129 v, 130. Sesión del 18 de julio de 1804: en la ciudad siempre habían sido los labradores los encargados de recoger el estiércol, pero hacía unos años que lo hacían «distintas compañías de holgazanes robustos» en perjuicio de los labradores. Además, no retiraban los animales muertos, despojos de vasijas, ni otros desperdicios

18 AMA. Libro de cabildos de 1804, ff. 129, 129 v. Sesión del 18 de julio. 
presidiarios que se encargaban de las obras del muelle junto a los presos que habitualmente acogía ${ }^{19}$.

Otra de las infraestructuras que mostraba serias carencias en 1804 eran los cementerios $^{20}$. En la epidemia de peste que sufrió Alicante en 1648, se construyó una zanja para enterrar los cadáveres en uno de los bancales al oeste del monte Benacantil. El municipio y el propio clero eran conscientes de que los enterramientos en las iglesias no eran convenientes, pero continuaron realizándose. Tras la epidemia de fiebre amarilla de 1804, se proyectó la obra del cementerio que se construyó en el llano de San Blas.

En 1803 la ciudad disponía entre sus recursos asistenciales de diez médicos - tres de ellos titulares de la ciudad—, ocho cirujanos — dos de ellos titulares-, ocho boticarios, tres albeitares ${ }^{21}$, sangradores y madrinas - de las que al menos una era titular del ayuntamiento ${ }^{22}$. Los médicos asalariados por el ayuntamiento tenían entre sus obligaciones asistir por turno al cuidado de los pobres enfermos de la ciudad, a los del Hospital de San Juan de Dios y a los enfermos de la cárcel ${ }^{23}$. Intervenían en las inspecciones y controles sanitarios de las embarcaciones que arribaban al puerto con enfermos cuya dolencia ofrecía dudas al «morbero». El resto de los médicos atendía otras necesidades de la ciudad: el doctor Martorell tenía a su cargo la asistencia de las 800 mujeres empleadas en la Real Fábrica de Cigarros y visitaba a diario el arrabal de San Antón y el médico Lanuza atendía el Hospital Militar ${ }^{24}$, llamado también Hospital Real.

El Hospital de San Juan de Dios mantenía un cierto número de camas para los pobres enfermos. Era asistido — por turno de meses - por los tres médicos y dos cirujanos titulares asalariados por la ciudad. El Hospital Militar acogía a los militares enfermos, pertenecientes al ejército o la armada, de todos los «achaques». La Casa de

19 AMA. Libro de cabildos de 1804, ff. 81, 81 v. Carta del 29 de mayo de 1804 del alcaide interino de las Reales Cárceles.

${ }^{20}$ Sobre el problema de los cementerios en relación con las medidas de sanidad terrestre, vid PEREZ MOREDA, V. (1980), Las crisis de mortalidad en la España interior. Siglos XVI-XIX, Siglo XXI, Madrid, pp. 425-429.

${ }^{21}$ AMA. Interrogatorio, año 1803, arm. 5, lib. 99, f. 87 v.

22 AMA. Recibían el nombre de madrinas o comadres las personas que asistían a las embarazadas, ayudaban en el parto, atendían a las mujeres después del mismo y a los niños. $c f$. CARBÓN, D. (1541) (Transcripción de SUSARTE, F. 1995), Libro del arte de las comadres o madrinas, Universidad de Alicante, Alicante. Libro de cabildos de 1804, ff. 175,175 v. Sesión de 16 de noviembre. J. Alvarez, solicitaba el empleo de madrina titular del ayuntamiento, encargada de asistir a las pobres de solemnidad, que hasta la fecha recaía en Vicenta Amat, que falleció víctima de la fiebre amarilla. Declaraba la solicitante ser de oficio madrina examinada por el Real Protomedicato.

23 AMA. Libro de cabildos de 1804, f. 184. Sobre la asistencia sanitaria pública en Alicante en el siglo XVIII vid. Perdiguero Gil, E.; Bernabeu Mestre, J. (1995), «La asistencia médica pública en el Alicante del siglo XVIII: Los médicos de la ciudad», Canelobre, 29/30, 165-175.

${ }^{24}$ Diario de Alicante, 9/XI/1927. (Serie de artículos titulados "La peste de 1804" escritos por Eduardo Irles Garrigós, empleado del Archivo Municipal de Alicante. Constaba de 29 capítulos). 
Misericordia ${ }^{25}$ atendía con dificultades a los pobres, tanto hombres como mujeres, a los huérfanos y a los expósitos y en la Casa de Santa María Magdalena se albergaba a las mujeres presas.

En 1803 las enfermedades más comunes eran las tercianas o fiebres intermitentes $^{26}$, siendo más benignas en la primavera que en el otoño. Afectaban, casi exclusivamente, a los habitantes pobres de los barrios, lo que se atribuía «a un régimen impropio en la vida» y no al influjo de la estación ni a otras causas.

La ciudad de Alicante en 1804, reunía tal como acabamos de comprobar, multitud de deficiencias que la hacían especialmente vulnerable a la propagación de enfermedades de carácter epidémico. Hay que destacar también la propia pasividad de las autoridades ante este tipo de problemas que se atendían, por norma general, cuando un acontecimiento de carácter extraordinario, como las epidemias, afligía a la ciudad.

En cuanto al entramado administrativo y político con el que la localidad tuvo que afrontar la epidemia de fiebre amarilla de 1804, Alicante era una ciudad de jurisdicción real y el gobernador, nombrado por el rey, era el justicia, la máxima autoridad y el corregidor de la municipalidad ${ }^{27}$. Poseía la responsabilidad de los aspectos, militares, civiles y sanitarios de la población y ostentaba la presidencia de la Junta Municipal de Sanidad. El cabildo municipal regía la vida de la ciudad ${ }^{28}$. Poseía ocho regidores de los que se designaban cada año dos comisarios de sanidad para encargarse del cuidado de la salud pública ${ }^{29}$. Las Juntas Provinciales de Sanidad constituían un organismo intermedio en asuntos de salud y la ciudad dependía de Valencia, cuya presidencia ostentaba el capitán general del reino. La máxima autoridad recaía en la Junta Suprema de Sanidad que en 1804 era presidida por el conde de Montarco, gobernador del Consejo de Castilla ${ }^{30}$. Las medidas que se adoptaban en las epidemias seguían, por tanto, una jerarquía cuyo máximo exponente era la Junta Suprema de

25 JOVER, N. C. (1863), Reseña histórica de la ciudad de Alicante (1821-1881), Alicante. (Edición facsímil, 1978, A. Soler Llorca, Alicante), p.109. En 1789 se expidió una Real Cédula que aprobaba las ordenanzas por las que debía regirse la Real Hermandad de Caridad.

26 AMA. Interrogatorio. Año 1803, arm. 5, lib. 99. Sobre este tema cf. Alberola RoMÁ, A. (1985), «Fiebres, ciencia médica y política sanitaria en el Alicante del setecientos», Canelobre, 4, 84-89; BERnABÉ GIL, D. (1986), «Tercianas y prevención pública en el Siglo de las Luces: el caso del Bajo Segura», Canelobre, 4, 77- 83 .

27 AMA. Expedientes y veredas, arm. 15 , lib. 37 , f. 637 v.

28 Sobre la organización municipal vid IRLES VICENTE, $\mathrm{M}^{\mathrm{a}}$ del C. (1996), Al servicio de los borbones. Los regidores valencianos en el siglo XVIII, Edicions Alfons El Magnànim/ IVEI, Valencia; ALBEROLA ROMÁ, A. (1993) «Centralismo borbónico y pervivencias forales. La reforma del gobierno municipal de la ciudad de Alicante (1747)», Estudis, 18, 147-171.

29 AMA. Libro de cabildos de 1804, f. 231. El nombre de los elegidos se comunicaba a la Junta Suprema de Sanidad, según lo ordenado en el reglamento de 11 de julio de 1758.

30 Sobre el origen y atribuciones de la Junta Suprema de Sanidad, $c f$. PESET, M. y PESET, J. L. (1972), Muerte en España. Política y sociedad entre la peste y el cólera, Seminarios y Ediciones, Madrid, pp. 32-35, 76-80. 
Sanidad, seguida de la Junta Provincial de Sanidad y la Junta Municipal de Sanidad. Las autoridades municipales eran las responsables, en última instancia, de ejecutar las medidas convenientes en caso de epidemia y de los múltiples gastos que ocasionaban, que el propio municipio se veía obligado a asumir.

\section{LAS MEDIDAS GENERALES CONTRA LA EPIDEMIA: AISLAMIENTO MEDIANTE COR- DONES SANITARIOS, PASAPORTES Y CUARENTENAS}

La declaración oficial del estado de epidemia requería el diagnóstico previo de la enfermedad, que debía ser aprobado por todos los médicos de la ciudad. La dificultad diagnóstica de la fiebre amarilla, que se presentó en 1804 por primera vez en Alicante, supuso un grave inconveniente. En contra del diagnóstico de una enfermedad epidémica ejercían presión los grupos con intereses económicos en la población, que a menudo coincidían con el poder local, puesto que las medidas adoptadas para controlarla - fundamentalmente aislamientos- paralizaban la vida comercial y laboral de la ciudad lo que provocaba numerosas pérdidas económicas y sumían en la miseria a gran parte de la población. Este último aspecto debía suponer para los médicos una gran responsabilidad puesto que si declaraban el estado de epidemia, sin tener la certeza absoluta, las medidas de aislamiento convertían en indigentes a gran parte de la población. Por ello, generalmente, una epidemia sólo se declaraba cuando era evidente e innegable.

Los conocimientos sobre el origen, la etiología, la transmisión y el carácter de la fiebre amarilla condicionaban las medidas político-sanitarias que se adoptaban para el control de las epidemias. También se valoraban distintos factores que podían provocar o agravar una enfermedad. Sin embargo - a pesar de los diversos tratados de la «nueva enfermedad» y las observaciones realizadas por los médicos- gran parte de las medidas que se adoptaron fueron las que tradicionalmente se habían usado en las epidemias, sin atender a su eficacia o perjuicios. Los médicos no llegaron a establecer con seguridad si la enfermedad poseía carácter «contagioso» o «epidémico», si debía considerarse «exótica» o importada, o si por el contrario se generaba por determinadas condiciones locales. El desconocimiento de la fiebre amarilla y de la manera de combatirla fue la causa de que la Junta Suprema de Sanidad optase por las tradicionales medidas de aislamiento, quema y fumigaciones, eficaces hasta cierto punto, $\mathrm{y}$ evitase experimentar nuevas teorías que criticaban las anteriores prevenciones ${ }^{31}$.

\footnotetext{
31 Ante la duda de que la fiebre amarilla se tratara de una enfermedad contagiosa se recomendaba «...sin atreverse a pronunciar afirmativamente sobre el contagio de esta enfermedad, y por consiguiente sobre su importación, ponen por principio que, en los casos inciertos, la autoridad debe obrar como si el contagio fuese absoluto y demostrado», En: HURTADO DE MENDOZA, M. (1820), Nueva monografía de la calentura amarilla o tratado médico teórico-práctico sobre la verdadera naturaleza, causas, síntomas,
} 
Declarada oficialmente la epidemia, una de las primeras medidas consistía en aislar a la población afectada mediante el establecimiento de un cordón sanitario que pretendía evitar que las personas enfermas, o que hubieran tenido «roce» con enfermos, extendiesen el mal a otros lugares, así como impedir que las mercancías u objetos declarados contaminados salieran de la población. Personas, objetos y mercancías eran estrechamente controlados; los individuos que querían desplazarse debían tramitar - como venía ocurriendo en anteriores epidemias - unas boletas de sanidad que garantizaran su estado de salud, donde se hacía constar el lugar de salida y la filiación del sujeto; si conducía mercancías, debía especificarse su origen y naturaleza. Este documento tenía que estar firmado por la justicia o cura párroco del pueblo de origen, del diputado — si pertenecía a un partido- y debía incluir la respuesta del justicia del pueblo al que se dirigían, en caso de ir a vender frutos ${ }^{32}$. En octubre de 1804 , una Real orden obligaba a las personas procedentes de pueblos infectados a realizar una cuarentena cuya duración se establecería considerando el día en que habían salido del mismo: «a los que hayan pasado más de cuarenta días desde la salida del pueblo se les someterá a una ligera cuarentena de 6 a 8 días», pasada la cual, se expurgarían y fumigarían sus ropas y efectos. Con estas cuarentenas se pretendía evitar que la enfermedad llegara hasta la Corte ${ }^{33}$. Para salir del Reino de Valencia, una Real orden regulaba que se debían solicitar los pasaportes en la primera secretaría de estado - a cargo de don Pedro Ceballos - por medio de don Domingo Izquierdo — capitán general del Reino de Valencia- a quien el gobernador de la ciudad debía remitirle, junto con las peticiones, las circunstancias personales de los sujetos que solicitasen dicho pasaporte indicando si concurría algún impedimento para concedérselo ${ }^{34}$.

Se establecieron lazaretos con diferentes objetivos: aislamiento de los enfermos, de convalecientes, de las personas que habían estado con algún enfermo o fallecido de fiebre amarilla y para los que se sometían a observación. Desde el comienzo de la epidemia, la Junta de Sanidad del Reino previno a los vecinos y Juntas del partido de Alicante de las cuarentenas que se debían cumplir:

modo de propagarse, y método curativo y profiláctico de los tifos, pero señaladamente de la especie llamada icteroides o fiebre amarilla, Vda. de Larumbe, Huesca, p. 80. Informe de los catedráticos Hallè, Le Roux y Chaussier, encargados por la Facultad de Medicina de París, a instancias del gobierno francés en 1817, para elaborar un informe sobre la fiebre amarilla que reinaba en algunos puertos de América.

32 AMA. Sanidad, leg. 1, núm. 2. Alicante, 17 de enero de 1805. Carta de Manuel Mirallas.

33 Real Orden referente a las cuarentenas, 9-X-1804 y Real Orden referente a las cuarentenas, 16-X1804, citados por PALAZÓN AZORÍN, J. M. (1977), La epidemia de fiebre amarilla de 1804 en la ciudad de Alicante, Valencia, tesis de licenciatura presentada en la Facultad de Medicina de la Universidad de Valencia, inédita. Dichos documentos no hemos podido localizarlos en el AMA.

34 AMA. Expedientes y veredas, arm. 15, lib. 36. Carta de Domingo Izquierdo a José Betegón, fechada en Valencia, el 2 de julio de 1805. 
Todas las personas que hayan salido de Alicante, desde el día 10 del corriente [septiembre] inclusive, deven ponerse inmediatamente en quarentena, eligiendo en cada pueblo el edificio que haya más a propósito distante de la población, cuidando de que se les asista con lo necesario y que las personas destinadas a su cuidado no salgan del recinto que se prescrive a los de la quarentena; advirtiendo que, los que se pongan en esta, han de satisfacer los gastos de alimentos y demás auxilios si tienen bienes o efectos para ello y los que no, se pagaran, los mui precisos, de los caudales públicos, entendiendo que estos han de ser los absolutamente indigentes ${ }^{35}$

Las mercancías — según su naturaleza y el peligro que comportaran— eran sometidas a diferentes tratamientos: los tejidos contaminados, o sospechosos de estarlo, solían quemarse, mientras que otros objetos se sometían a cuarentenas, se ventilaban o se fumigaban para librarlos del «miasma» de la enfermedad. Los dueños de los efectos retenidos debían satisfacer los gastos que ocasionaba su almacenaje, custodia y fumigación, con excepción de los que viajaban por orden del rey ${ }^{36}$.

Para que el trigo, destinado a los molinos, la harina o la leña se introdujeran a través del cordón sanitario se requería una licencia superior. También la correspondencia era retenida y sólo los pliegos del real servicio podían franquearlo, previamente pasados por vinagre ${ }^{37}$.

Estas cuarentenas, de personas y de mercancías, eran sumamente gravosas para la población y contribuían a empeorar la situación económica de los más desfavorecidos. Algunos habitantes optaron por cumplir la cuarentena en casas de campo de los alrededores o en pueblos cercanos, siempre que dispusieran de medios económicos para costear sus alimentos y pagar una guardia de día y noche a la puerta de la casa que garantizara que nadie salía mientras duraba la cuarentena ${ }^{38}$.

Los lazaretos llamados de precaución o de barracas se instalaron en los campos o huertas cercanos a las poblaciones y las familias podían acompañar a los enfermos convalecientes para cuidarlos ${ }^{39}$.

35 AMA. Sanidad, leg. 1, núm. 8 bis. El 21 de septiembre de 1804 se comunicaron estas órdenes a las justicias de Santa Faz, Muchamiel, Busot, Agost, San Juan y Villafranqueza.

36 AMA. Sanidad, leg. 1, núm. 7. Circular fechada en Madrid en 5 de junio de 1805, relativa a la orden de S.M. de 18 de junio de 1804, que regulaba el paso de personas y efectos procedentes de los pueblos que padecieron el contagio de la fiebre amarilla en el año anterior.

37 Diario de Alicante, 14 /XI/1927.

38 AMA. Sanidad, leg. 1, núm. 8 bis.

39 Archivo de la Real Academia Nacional de Medicina de Madrid (desde ahora RANM). Fol. 8, leg. 20, doc. 1156. Observaciones sobre la fiebre amarilla padecida en Alicante en 1804 y que se manifestó posteriormente en la misma ciudad y otros pueblos. Informe elaborado por José Alcaraz y Tomás Lanuza, médicos alicantinos fechado el 22/VI/1816 (desde ahora Observaciones..). Los médicos habían observado que en estos lazaretos de barracas, las personas que cuidaban a los enfermos de su propia familia y que convivían en la misma barraca, nunca habían contraído la fiebre amarilla. 
Las medidas de sanidad marítima eran las más institucionalizadas, mejor legisladas y en general de las que se cumplían con mayor rigor. El puerto también era objeto de aislamiento, circunstancia que dificultaba su actividad. Se creía que este tipo de enfermedades «exóticas» - la fiebre amarilla constituía un ejemplo— tenían su origen en las embarcaciones que procedían de lugares infectados, por lo que se ordenaban cuarentenas preventivas de distinta duración según los casos ${ }^{40}$.

A pesar de que las normas de sanidad eran muy rigurosas no siempre se cumplían. Un ejemplo lo constituye la carta que, el 17 de julio de 1805, escribió el gobernador de Alicante al comisario de sanidad por haber advertido la noche anterior poca vigilancia en la caseta del muelle. Ordenaba reprender a los responsables y recordarles a los morberos y marineros de sanidad su obligación de rondar la bahía de noche y que cuando el mar no les permitiera salir debía siempre quedar un vigilante en el muelle ${ }^{41}$.

\section{EL CURSO DE LA EPIDEMIA: ACTUACIONES EN LA CIUDAD ANTE LA DECLARACIÓN OFICIAL DE LA FIEBRE AMARILLA}

Hemos descrito las prevenciones que, de una manera más o menos institucionalizada, se dictaban cuando se sospechaba la posibilidad de un contagio. Estas medidas de aislamiento eran impuestas a la población en casos de epidemia por las autoridades provinciales y centrales y su objetivo era impedir el contagio de otras poblaciones. El efectivo aislamiento de la población era responsabilidad del gobernador y de los designados en la ciudad como encargados de alguna de las medidas - como el cordón sanitario o las fumigaciones. En general cualquier iniciativa local requería la aprobación de las autoridades superiores.

Las autoridades municipales, además de aislar convenientemente la población para evitar la extensión del brote a otras poblaciones, debían procurar la subsistencia de los vecinos indigentes y costear toda la infraestructura que estas circunstancias hacían precisa, recaudando los fondos necesarios de las personas con mayores recursos de la población, tarea no siempre fácil.

En la relación de las medidas adoptadas o ejecutadas por la ciudad hemos respetado el orden cronológico en que se instauraron por revelar la gravedad de la situación en cada momento.

\footnotetext{
40 Sobre las medidas preventivas marítimas, ver: RODRIGUEZ OCAÑA, E. (1988), «La cuestión del lazareto marítimo permanente en la España del siglo XVIII, de Cádiz a Mahon», Asclepio, XL, 1, 265-276. AMA. Sanidad, leg. 1, núm. 7. Circular, Madrid 5 julio 1805, donde se comunican Reales órdenes de 18 de junio de 1805 , relativas al paso de personas y efectos procedentes de pueblos que padecieron el contagio en 1804. El reglamento de 11 de julio de 1758 especificaba los empleados y lo que debían percibir al año o por visita sanitaria de inspección a los barcos y demás normas para garantizar la salud del puerto.

${ }^{41}$ AMA. Sanidad, leg. 1, núm. 11. Alicante, 18 de julio de 1805.
} 
El 13 de septiembre de 1804 se declaró oficialmente la existencia de la fiebre amarilla en la ciudad de Alicante y el gobernador José Betegón —responsable de la salud de la población- adoptó las prevenciones necesarias mientras esperaba las órdenes superiores. El mismo día 13 ordenaba al alcalde mayor que investigase las causas del contagio ${ }^{42}$.

La epidemia se inició en el centro de la ciudad, en la calle Mayor, donde vivían las personas con mayores recursos. Una de las primeras preocupaciones del gobernador, fue garantizar el suministro de víveres a la población, especialmente a los indigentes privados de todo recurso. El 14 de septiembre Betegón dictó las primeras normas, difundidas mediante un bando, que intentaban impedir la huida masiva y garantizar el aprovisionamiento de los habitantes:

Que ningún escribano, ni otro empleado público, pueda ausentarse de la ciudad sin licencia escrita bajo la pena de privación de su oficio (...) Los tenderos de comestibles, confiteros y demás de esta especie no podrán ausentarse ni cerrar sus tiendas; quienes desobedezcan tendrán multa de 200 pesos y quedarán privados para siempre de volver a sus tiendas ni a otra oficina pública (...) Que todos los vecinos, y también los forasteros, tengan libertad para salir a comprar y vender géneros a precios prudentes y moderados ${ }^{43}$

La Junta de Sanidad ${ }^{44}$ dispuso el reparto de raciones de pan y carne a los «pobres enfermos convalecientes» mediante unas papeletas que iban firmadas por el médico Ramón Ferrán y Francisco Carbonell, diputado de justicia de la ciudad ${ }^{45}$.

El cabildo del ayuntamiento — reunido en la iglesia de Santa María— hizo pública la Real Orden que mandaba hacer rogativas públicas, cesando mientras tanto todos los festejos públicos. Se acordó obedecerla, pero realizándolas secretamente por el consejo de la Junta de Sanidad de impedir las aglomeraciones ${ }^{46}$.

Se estableció el cordón sanitario que debía cercar la ciudad, rodeando a la población siguiendo la costa y a través del campo alicantino con los soldados del regimien-

\footnotetext{
42 PAlazón Azorín, J. M. (1977). Utilizaremos de este trabajo los documentos que nos permitan reconstruir las medidas político-sanitarias adoptadas por la ciudad y que en la actualidad ya no se encuentran en el Archivo Municipal de Alicante.

43 Diario de Alicante, 12/XI/1927. Citado entre comillas. Bando de fecha 14/IX/1804, citado por PALAZÓN AZORÍN, J. M. (1977). No se encuentra ya entre los documentos del AMA.

${ }^{44}$ Diario de Alicante, 12/XI/1927. La Junta de Sanidad se refugió en el aula capitular de la Iglesia de Santa María, nada más declararse la epidemia.

45 AMA. Libro de cabildos de 1804, ff. 185, 185 v. Memorial del 16 de noviembre de 1804, de Francisco Carbonell, maestro de obras por la Real Academia de San Carlos y diputado de justicia de la ciudad, solicitando el empleo de maestro titular de obras del ayuntamiento, por fallecimiento del titular Stanislao Pérez, diputado del común.

46 AMA. Libro de cabildos de 1804, f. 160 v. Sesión extraordinaria del 19 de septiembre. La Real Orden iba fechada en San Ildefonso a 12 de septiembre de 1804, por lo que no iban dirigidas en especial a la epidemia de Alicante, que se declaró oficialmente el día 13, sino a las sufridas en el territorio español con anterioridad.
} 
to de América que obedecían las órdenes del mariscal Pedro de Buck y O’Donell —nombrado comandante general del cordón sanitario- que residió en Elche durante la epidemia. También colaboraban personas civiles. Las órdenes para garantizar la eficacia del cordón fueron impuestas por el conde de Montarco — desde la Junta Suprema de Sanidad - siendo las mismas que se adoptaron desde 1800 en las epidemias de Cádiz, Málaga y Cartagena ${ }^{47}$. Mediante estacas, cuerdas y cordón se compuso el cerco, estableciéndose «puntos de barraca» por donde debían pasar obligatoriamente las personas que pretendían entrar o salir, previa presentación de sus boletas de sanidad ${ }^{48}$.

Para facilitar el aprovisionamiento de las personas encerradas por el cordón sanitario el comandante general del mismo señaló los días y los lugares donde debían celebrarse los mercados, que eran controlados por soldados y personas que colaboraban en salvaguardar el aislamiento ${ }^{49}$. El cabo de vigilancia poseía instrucciones para que las ventas de víveres se efectuasen «de modo que los vendedores y compradores no tengan roce y haciéndose pasar por vinagre el dinero» ${ }^{50}$.

El día 16 de septiembre se estableció en el convento de San Francisco y hospicio de la casa santa el lazareto que debía albergar a los enfermos de la fiebre amarilla ${ }^{51}$. Se nombró para dirigirlo al coronel del regimiento de infantería de América, Francisco Fulgosio, y se dotó con un contralor, un cirujano, dos boticarios, un lavandero, dos ayudantes de sangrador, dos húsares para la cremación de las ropas de enfermos y difuntos, algunas enfermeras y sirvientas y «doce presidiarios [a los] que, por cuatro reales de jornal más la amenaza de ser pasados por las armas en caso de evasión, se les obligaba a trasladar a las personas apestadas y a conducir a los cadáveres hasta las zanjas donde reciben sepultura piadosa». Se designó médico del lazareto a Pedro Sebastiá y los religiosos franciscanos cuidarían del servicio y consolación de los enfermos. José Serrano ejerció de cirujano en el lazareto, que lo era del regimiento de América y ya en la epidemia de Málaga se había comportado «con caridad y denuedo» ${ }^{52}$

El mismo 16 de septiembre se ordenó que todos los enfermos debían trasladarse al lazareto de San Francisco para poder prestarles mejor asistencia, comenzando por

47 Diario de Alicante, 14/XI/ 1927. La expresión «campo alicantino» es utilizada en el artículo revisado en el periódico y, en caso de ser una trascripción parcial de algún documento, podría corresponder al Camp d'Alacant, comarca tradicional de la ciudad.

48 AMA. Sanidad, leg. 1, núm. 7 bis. Carta fechada en Elche a 17 de octubre de 1804. Noticias sobre la línea del cordón de Tibi.

49 AMA. Sanidad, leg. 1, núm. 7 bis. Diario de Alicante, 14 /XI/1927. El Palamó o Villafranqueza.

50 Diario de Alicante, 14 /XI/1927. Aparece entre signos de cita literal, aunque no indica el documento.

51 AMA. Sanidad, leg. 1, núm. 5. En Archivo Histórico de Orihuela (AHO). FM. D. 1239, núm. 13.

52 Diario de Alicante, 15/XI/1927. Por diversos testimonios del contralor del lazareto, al parecer, sus funciones competían a la administración y el orden en el lazareto y, además, supervisaba al personal que atendía a los enfermos. 
los de la calle Mayor ${ }^{53}$. Además, las personas cuyos recursos no permitieran una regular asistencia ni el mantenimiento de los guardias de la cuarentena debían trasladarse a un lazareto; se debían quemar las camas y los muebles de las habitaciones de los enfermos y fallecidos ${ }^{54}$, purificando inmediatamente las casas, y sus familias debían guardar la cuarentena precisa. Así mismo, se trasladaría a los lazaretos a los pobres de solemnidad, a los que habitasen en casas sucias, reducidas, lóbregas y sin ventilación, y a cuantos «carecieran de ropa blanca». Quedaba prohibido el toque de campanas «para que los vecinos no se amedrenten ${ }^{55}$.

El día 20 de septiembre, Betegón reiteraba la orden de quemar las ropas y objetos pertenecientes a los que fallecían «con accidente sospechoso», precisando la forma en que debía realizarse, dejando los demás muebles para la purificación ${ }^{56}$.

El municipio organizó una comisión para proteger la propiedad de los vecinos que abandonaban sus viviendas y garantizar su aislamiento hasta que se realizaran las fumigaciones que, en teoría, debían evitar el peligro de un nuevo contagio. El funcionamiento de esta comisión fue descrito por el cerrajero que pertenecía a la misma. Cuando fallecía el cabeza de la casa o se abandonaba alguna casa el regidor José Albelda, como comisario de barrio y acompañado por un escribano, mandaba al cerrajero cerrar las casas «claveteando los balcones y ventanas y poniendo candados a las puertas $\rangle^{57}$. Todas las ropas y demás efectos de los muertos de fiebre amarilla, debían quedar en los cuartos donde fallecían sin poder ser tocadas hasta que fueran fumigadas. Las llaves debían entregarse a los correspondientes alcaldes de barrio que eran los responsables de que esta norma se cumpliera ${ }^{58}$.

En la primera mitad de septiembre, para evitar el intrusismo profesional se recordaba que los «profesores» debían limitarse a curar las enfermedades que su facultad

53 Diario de Alicante, 12/XI/1927 y PALAZÓn Azorín, J. M. (1977). Estas medidas, al parecer, se extraen del dictamen facultativo de fecha 16/IX/1804, en el que los médicos: Francisco de Paula Martorell, Antonio Villegas, José Alcaráz, Tomás Lanuza, Joaquín Gonzalez, José Coderch y Francisco Lloret, elaboraron un comunicado con las medidas recomendadas a adoptar, que la Junta de Sanidad se encargó de hacer cumplir. Dicho documento no hemos podido localizarlo en el AMA.

54 AMA. Sanidad, leg. 1, núm. 8 bis. El 16 de octubre de 1804, el cabo del barco de sanidad informaba a Betegón de la quema de un barco, barriles vacios, cofres de pasajeros, etc. que le había ordenado.

55 Diario de Alicante, 12/XI/1927. Los mecanismos de control social haciendo servir la enfermedad como instrumento pueden consultarse en: Bernabeu Mestre, J.; RAMOS SEgURA, J. R. (1995), «Malaltia, poder i control social: El desallotjament de la barriada alacantina de les províncies amb motiu de la grip de 1918», Actes de les III Trobades d'Història de la Ciència i de la Tècnica als Pä̈sos Catalans, SCHCT, Barcelona, 215-221.

56 Diario de Alicante, 16/XI/1927.

57 AMA. Libro de cabildos de 1804, ff. 186-187.

58 AMA. Sanidad, leg. 1, núm. 5 bis. Año 1804. Documento sin fechar con el encabezamiento: Prevenciones que deben hacerse. 
les permitía ${ }^{59}$. Para recoger la información sobre el curso de la epidemia, los facultativos debían cumplimentar unos partes diarios, que se les facilitó, y llevar el control de las calles, manzanas, números de las casas y nombres de los enfermos, especificando la enfermedad que padecían; los párrocos debían dar noticia a diario sobre las personas de su feligresía que hubieran fallecido, con sus nombres, calles y números de sus casas. Todas las noches a las 8 , los curas debían entregar dichos partes al caballero comisionado que la ciudad destinase a tal efecto. Los fallecidos debían conducirse en carros por la noche al cementerio de la colegial de San Nicolás, extramuros de la ciudad.

Se ordenó evitar «totalmente» la comunicación de la calle Mayor con el resto de la ciudad y sus arrabales. El regidor Vicente Navarro se encargó de suministrar los víveres a los vecinos que permanecían en el interior de la calle incomunicada.

La ciudad se dividió en sectores y a cada uno de ellos se le asignó un médico junto con un boticario o cirujano. El médico Lloret y el boticario Antonio Martrás se ocuparon de los barrios de Santa Cruz y San Roque; Francisco de Paula Martorell y el boticario Moró se encargaron del arrabal de san Antón; la calle Mayor e inmediaciones fueron atendidas por el doctor Lanuza y el cirujano José Serrano; la Villavieja y el Raval Roig fueron encomendados al médico Alcaráz y a Francisco Simó; el médico José Coderch atendió el arrabal de San Francisco y Pedro Sebastiá fue destinado al lazareto de San Francisco. El resto de la ciudad fue atendido por los médicos Joaquín González y Antonio Villegas ${ }^{60}$. Los responsables de estas primeras medidas adoptadas fueron los médicos y cirujanos, los curas o párrocos, los regidores destinados al efecto y los alcaldes de los barrios. Se nombraron comisiones para la quema de camas, ropas y otros objetos, para la apertura de zanjas, para el enterramiento de los cadáveres y para la provisión de comestibles, pan y la limpieza de las calles. Los médicos de la ciudad debían reunirse todas las noches en «academia» para intercambiar impresiones ${ }^{61}$.

La organización del Lazareto de San Francisco fue conflictiva debido al gran número de personas que debía albergar y a la carencia de medios para alojarlos y personas suficientes que les atendieran. El día 14 de septiembre, el director del lazareto solicitó al gobernador 50 camas «para las primeras urgencias» y seis presos - de los que trabajaban en las obras del muelle- para que prestaran servicio en el mismo, pues se lamentaba de que «por más ventajas que he proporcionado a los vecinos de

\footnotetext{
${ }^{59}$ Había problemas sobre las facultades de médicos, cirujanos, sangradores y demás personas dedicadas de una u otra forma a la atención sanitaria de la población. A lo largo de 1804 en las actas del Ayuntamiento de Alicante, varios médicos y cirujanos presentaron los títulos acreditativos, que quedaron registrados en el ayuntamiento y devueltos al propietario.

${ }^{60}$ Diario de Alicante, 12/XI/1927. Se acordó tapiar la calle Mayor.

${ }^{61}$ Comisiones nominadas, 1804, citado por PALAZÓN AZORÍN, J. M. (1977). Consta el nombramiento de Fulgosio y otras comisiones. No lo hemos localizado en el AMA.
} 
este pueblo para que concurran a este servicio, ninguno quiso aceptar» ${ }^{62}$. A poco de su nombramiento, el coronel Fulgosio pidió al gobernador ser sustituido como director del lazareto, alegando razones de su empleo militar. Se aceptó su renuncia y el día 20 de septiembre fue reemplazado por José Rodríguez ${ }^{63}$. A partir del 15 de septiembre, comenzaron a llegar cartas de los pueblos cercanos interesándose por la enfermedad que se padecía y solicitando noticias al respecto ${ }^{64}$. Elche y Aspe ofrecieron su colaboración, facilitando los alimentos que la Junta de Sanidad de Alicante les había pedido.

El 17 de septiembre Joaquín Bermúdez, administrador de rentas, solicitó al gobernador el cierre de la aduana debido a la huida de la mayor parte de los propietarios de las principales casas de comercio y de los vecinos pudientes ${ }^{65}$. Betegón era reacio a paralizar las actividades comerciales de la ciudad y sometió la propuesta de Bermúdez a la valoración del alcalde mayor que se mostró contrario, ya que, según decía «no está cortado el comercio por mar ni tierra». Finalmente, una orden de la capitanía general de Valencia mandó cerrar el puerto y la aduana, que se verificó el 22 de septiembre ${ }^{66}$, reduciéndose los recursos para la supervivencia de la gran mayoría de los habitantes que aún permanecían en la ciudad, prueba de que el aislamiento - independientemente de las consecuencias para la población- era la mayor preocupación de las autoridades ajenas a la ciudad de Alicante, para asegurar su propia salud.

Para garantizar la seguridad en el cerco que aislaba a la ciudad, el gobernador de Alicante en un bando el día 20 de septiembre, ordenaba que «nadie se acerque hasta el cordón llevando armas de fuego». Se castigaba a los infractores a la pena de cuatro años de servicio en las obras del muelle y a la confiscación de «sus bienes a beneficio de los gastos de las actuales enfermedades y socorro de pobres» ${ }^{67}$.

Otro bando municipal, del día 24 de septiembre, reiteraba la sospecha de que el contrabando era el origen de los males que se sufrían y se solicitaba a la población

${ }^{62}$ Carta del encargado del lazareto, 14-IX-1804, dirigida a Betegón, citado por PALAZÓN AZORÍN, J. M. (1977). No lo hemos encontrado en el AMA. (Recordemos que el lazareto se abrió el 16 de septiembre de 1804.)

${ }^{63}$ Nombramiento de nuevo director del lazareto, 20-IX-1804, citado por PALAZÓN AZORín, J. M. (1977). No se encuentra ya en el AMA.

${ }^{64}$ Diversas cartas: Ayuntamiento de Elche, 15-IX-1804; Ayuntamiento de Aspe, 15-IX-1804; Ayuntamiento de Elche ofreciendo..., 18-IX-1804; Ayuntamiento de Elche a la Junta de Sanidad de Alicante, 22-IX-1804; Ayuntamiento de Orihuela, 15-IX-1804; Junta de Sanidad de Orihuela, 25-IX-1804, citadas por PALAZÓN AZORÍN, J. M. (1977). No las hemos podido localizar en el AMA.

65 Carta del administrador de rentas, 17-IX-1804, citada por PALAZÓN Azorín, J. M. (1977). En dicha carta el administrador de rentas solicitaba el cierre del puerto y la aduana ya que se había registrado un caso de fiebre amarilla en el mismo. El documento no lo hemos podido localizar en el AMA.

66 AMA, Sanidad, arm. 19, leg. 65, núm. 21.

${ }^{67}$ Diario de Alicante, 16/XI/1927. Bando del Gobernador José Betegón prohibiendo..., 14-X-1804, citado por PALAzÓn Azorín, J. M. (1977). No lo hemos localizado en el AMA. 
que delatara el lugar donde se hallaban escondidos dichos efectos, pues se aseguraba que «mientras no se sepa su paradero, ha de continuar el contagio» ${ }^{68}$.

Durante el mes de octubre la epidemia se intensificó. El 3 de octubre el gobernador emitió un bando que dictaba órdenes referentes a policía sanitaria y para el socorro de los más necesitados ${ }^{69}$. Entre ellas destacaban: el uso de «los ácidos, los aromas y el salitre, evaporar mucho vinagre, hacer sahumerios cristianos y quemar pólvora, debiendo también tirarse algunos cañonazos a la inmediación del pueblo», para purificar el aire. Se reiteraba la importancia de quemar la ropa de los contagiados y de los que ingresaban en los hospitales, donde se les daría una camisa nueva y un jergón. Se debía disponer en todas las «tiendas de abastos y boticas» de recipientes con vinagre para poder purificar las monedas y aquello que fuera preciso. Mediante una papeleta, se darían gratuitamente las medicinas a los pobres que se curaban en sus casas, debiendo acudir a la «botica de Domingo Moró», en la plaza de San Cristóbal. El síndico personero proporcionaría los alimentos a los pobres. Se ordenaba el exterminio de los perros por considerarse perjudiciales «en tiempos de contagio». Los que vivieran con un enfermo que no hubiera sido declarado serían castigados. Se prohibían las reuniones de personas por contribuir a la extensión de la enfermedad. Para evitar la aglomeración en las iglesias, Betegón recomendaba a los vecinos: «pueden desde sus casas implorar los divinos auxilios para que Dios mejore la suerte de este pueblo, como que oye los corazones de los verdaderos católicos desde cualquiera sitio o retiro, y los que piensen lo contrario son unos asesinos del común».

La magnitud que había adoptado el brote epidémico y la necesidad de hacer cumplir las normas prescritas parecen ser la razón de que se incluyera, en el bando anterior, la amenaza de que serían «pasados por las armas» los criados o sepultureros que «robasen o guardasen para sí alguna cosa». El tráfico con los objetos sospechosos de ser contagiosos debía ser bastante frecuente pues se perseguía reiteradamente y con dureza. Una Real Orden, del 11 de octubre de 1804 lo castigaba con la pena de muerte ${ }^{70}$.

El día 10 de octubre falleció el alcalde mayor de Alicante, Rafael Echeverri, víctima de la epidemia. La mayoría de los regidores habían huido o se encontraban enfermos. La falta de sus componentes provocó que las sesiones del cabildo del ayuntamiento se suspendieran y el gobernador escribió a Godoy y a los ministros del gobierno, el día 13 de octubre, comunicando la situación en que se hallaba la ciudad:

${ }^{68}$ Diario de Alicante, 16/XI/1927.

69 Bando del Gobernador Betegón en el que se dan órdenes..., 3-X-1804, citado por PALAzón AzORíN, J. M. (1977). No lo hemos encontrado ya en el AMA. También se trascribe en Diario de Alicante, $18 / \mathrm{XI} / 1927$

70 AHO. FM. D. 1239, núm. 13. Bando del capitán general de Valencia donde se comunica por orden del conde de Montarco, la pena de muerte por contrabando, fechado en Madrid a 11 de octubre de 1804. 


\begin{abstract}
...los rexidores ninguno concurre a nada; uno de ellos ha muerto, dos se han ausentado, otros dos se mantienen asustados en sus casas; de modo que solo cuento, para lo mucho que haya que atender, con los militares y cuatro vecinos honrados a quienes tengo encargados los ramos de abastos y los barrios de este pueblo para la mejor asistencia de los enfermos. De médicos hay escasez y he pedido al capitán general de este reyno me envíe algunos (...) La pobreza se aumenta, como que falta el tráfico del puerto de que viven, y ya se remedia con 500 reales diarios, que es muy poco, por cuenta del caudal de gastos de las enfermedades ${ }^{71}$
\end{abstract}

Se autorizó al gobernador a nombrar provisionalmente las personas que considerase a propósito para los cargos de alcalde mayor y regidores ${ }^{72}$. El 14 de octubre, José Betegón ordenó el cierre de la fábrica de cigarros $^{73}$.

A finales de octubre, nuevas órdenes ordenaban mejorar la limpieza e higiene del matadero y de las carnicerías, tal y como habían recomendado los médicos de la ciudad. Algunas disposiciones se destinaban a mantener la disciplina en el matadero, castigándose la insubordinación con penas de «80 reales hasta 4 años de prisión en Cartagena». El robo se castigaba con pena de 100 palos en la espalda. También se prescribía la limpieza «escrupulosa» de las distintas dependencias del matadero, vertiendo después el agua empleada en el mar ${ }^{74}$.

El 20 de octubre llegó a Alicante el médico Ambrosio Lorite, enviado por la Junta Suprema de Sanidad en calidad de director de la epidemia, quien se encargaría de los métodos de curación, disposición de cuarentenas, fumigaciones y ventilación para impedir el contagio, así como la vigilancia del Lazareto, de las casas de convalecencia y de los enfermos de la ciudad y arrabales ${ }^{75}$. El 23 de septiembre había llegado el catedrático Tomás Tatay desde Valencia, el capitán general del Reino le recomendaba a Betegón: «que se mantenga ahí hasta la llegada de Lorite, médico de Sevilla, nombrado director de la epidemia por la Junta Suprema. Que ambos consulten y acuerden el método a seguir» ${ }^{76}$, sin embargo el 25 de septiembre Tatay pretendía marcharse ya de Alicante. Betegón le denegó el pasaporte que solicitaba y lo envió a

71 Datos obtenidos del documento: Antecedentes sobre las órdenes..., 13-X-1804 y Carta del Gobernador José Betegón, 8-X-1804, citados por PAlazón Azorín, J. M. (1977). En el Diario de Alicante, 18/XI/1927, en una carta que se trascribe en parte, se decía que el regidor murió el día 13 y que habían fallecido los médicos Coderch y Villegas.

72 AMA. Libro de cabildos de 1804. Sesión de 30 de octubre: lectura de la Real Orden de 17 de octubre en San Lorenzo y firmada por José Antonio Caballero. Nombramiento de Leonardo Alberola, 22X-1804, citado por PALAZÓN AZORÍN, J. M. (1977). Alberola desempeñó el cargo interinamente hasta que el 12 de noviembre de 1804, en sesión de cabildo, tomó posesión del cargo con «calidad de por ahora»: AMA. Libro de cabildos de 1804, f. 172.

73 Diario de Alicante, $18 / \mathrm{XI} / 1927$

74 Estos datos se atribuyen a órdenes publicadas por el capitán Gabriel Alonso, encargado por el gobernador para este fin, contenidas en el documento: Ordenes encaminadas a la limpieza e higiene, 28-X1804, citado por PALAZÓn AZORín, J. M. (1977). No lo hemos localizado en el AMA.

75 AMA, Sanidad, arm. 19, leg. 65, núm. 14.

76 AMA, Sanidad, arm. 19, leg. 65, núm. 21. Diario de Alicante, 18/XI/1927. 
una casa de las inmediaciones de la ciudad, pero no debió tardar mucho en irse pues el día 29 ya se había marchado. Ambrosio Lorite se alojó en la calle Labradores. Se confiaba en que sus conocimientos sobre la fiebre amarilla contribuirían a mejorar la situación de la ciudad y se depositaron en él nuevas esperanzas ${ }^{77}$.

A finales de octubre —el día 30- se reorganizó el ayuntamiento y en sesión de cabildo se dio posesión «en calidad de por ahora» al alcalde mayor, los regidores, los diputados y el síndico personero ${ }^{78}$, para «que los asuntos del público y del resguardo de la salud, no padezcan atraso por falta de regidores ${ }^{79}$. De los regidores anteriores, uno había muerto y tres se encontraban ausentes. Las vacantes fueron cubiertas por cuatro militares y dos paisanos, además de Vicente Berenguer de Marquina, que permanecía al frente de su regiduría. De los diputados de la ciudad, uno de ellos había muerto y dos se encontraban ausentes, por lo que se nombró diputados en «calidad de por ahora» a los que ya se hallaban colaborando como tales. El síndico personero del común, que también había fallecido, fue sustituido por un militar. Repartidos los cargos, se procedió a la asignación de los empleos. Los recién incorporados asumieron las comisiones que estaban conferidas a los que respectivamente sustituían, además de aquellas que el secretario del ayuntamiento les comunicara como propias ${ }^{80}$.

En el mes de noviembre fue remitiendo la epidemia —como puede verse en la gráfica 1 que registra los fallecidos diariamente a causa de la epidemia-. Una de las prioridades fue procurar restablecer la vida pública de la ciudad. Al ayuntamiento llegaron multitud de memoriales — conservados en el libro de cabildos de 1804solicitando los empleos municipales cuyos titulares habían fallecido. Aunque el número de muertos por la fiebre amarilla descendió en gran medida, a mediados de noviembre nuevas disposiciones de la Junta de Sanidad prohibían el paso de vecinos, entre la ciudad y las casas de la huerta, para «evitar un nuevo brote». Se castigaba el regreso a la ciudad con una multa de 400 ducados y los que habían huido de la misma no podían volver, ni alojarse en el barrio de San Antón, bajo penas de «200 pesos a los nobles y 4 años de prisión a los plebeyos»; con iguales penas se castigaría a los que recibiesen «ropas y colchones procedentes de los pueblos y lugares vecinos». La responsabilidad de estas medidas recayó sobre los alcaldes de barrio y ministros de justicia y para promoverlas se ofreció una recompensa de 600 reales a los delatores,

\footnotetext{
77 Diario de Alicante, 18/XI/1927. Correspondencia de Domingo Izquierdo al gobernador Betegón.; Correspondencia de Pedro Buck a Betegón: «Compadezco a vuesa merced entre tanta confusión y disposiciones de facultativos y pido a Dios, de todas veras, que el nuevo físico acierte a la total curacion para vivir con sosiego»!.

78 El síndico personero del común, era el encargado de proteger y velar por el benefício público y los intereses de la población. Comunicaba en el cabildo municipal las quejas o reclamaciones que recibía.

79 AMA. Libro de cabildos de 1804, ff. 161v, 162. Sesión del 30 de octubre de 1804.

80 AMA. Libro de cabildos de 1804, ff. 161v, 162, 162 v. Sesión del 30 de octubre de 1804.
} 
con promesa de mantenerlos en el anonimato ${ }^{81}$. Los barrios de San Francisco, San Antón y el Raval Roig -extramuros-, fueron objeto de un intenso control para evitar la entrada a la ciudad. En las puertas de la «Reyna», San Francisco, del Muelle y Santa Ana una guardia formada por un oficial, dos dependientes de rentas y un vecino de la ciudad reconocían a todos los que pasaban, cumpliendo instrucciones de Sanidad. «Las citadas puertas se cerrarán al ponerse el sol tocando la llamada, como en las plazas de guerra, y se abrirán al romper el día» ${ }^{82}$.

Durante el mes de noviembre los encargados municipales trataron de recaudar de los hacendados y comerciantes de Alicante medio millón de reales de vellón, en calidad de reintegro ${ }^{83}$. Comenzaron a planificarse las fumigaciones que debían realizarse sobre dependencias y efectos, para poder declararse el estado de salud en la ciudad. El 18 de noviembre, el gobernador reiteraba la prohibición de enterrar en el interior de los templos ${ }^{84}$, práctica que condenaba así mismo Ambrosio Lorite ${ }^{85}$.

A finales de noviembre la epidemia había concluido prácticamente y los comerciantes comenzaron a presionar a Betegón para que tramitase la celebración del Te Deum de acción de gracias, que se realizaba tras finalizar la misma ${ }^{86}$.

En estas fechas el conde de Montarco solicitó al corregidor de Alicante el número de personas que habían enfermado, fallecido y curado, con motivo de la epidemia, así como el número — si no podía ser exacto aproximado - de habitantes que había en la población con anterioridad ${ }^{87}$. El 24 de diciembre se remitió a Valencia y Madrid el «Estado General», del número de enfermos y fallecidos a causa de la epidemia ${ }^{88}$ (tabla 1).

El mes de diciembre se caracterizó por la necesidad apremiante ante la miseria de la población de abrir el puerto y la fábrica de cigarros y por acelerar las fumigaciones previas a la apertura de la comunicación de la plaza de Alicante. El gobernador comenzó las gestiones, dirigidas a las autoridades competentes, para lograr estos objetivos. El 1 de diciembre dirigió un escrito a la Junta Suprema de Sanidad y otro al capitán general del Reino de Valencia, solicitando el restablecimiento del tráfico comercial del puerto y aduanas. Como aval de la salud, que de nuevo gozaba la población, aportaba los partes médicos de los últimos cuatro días del mes de noviembre

81 Bando del Gobernador José Betegón, 16-XI-1804, citado por PALAZÓN AZORíN, J. M. (1977). También se refleja en Diario de Alicante, 1/XII/1927.

82 Diario de Alicante, 1/XII/1927. Datos que hacen referencia al bando del día 16 de noviembre de 1804.

83 AMA. Sanidad, leg. 1, núm. 1, h.5.

84 Carta de José Betegón a Andrés Gómez Davila, 18-XI-1804, citada por PALAzón Azorín, J. M. (1977).

85 RANM, Fol., 4, leg. 20, doc. 1173. Carta de Ambrosio Lorite fechada en Alicante a 17-XI-1804.

86 Carta del capitán general del reino de Valencia, 20-XI-1804, citada por PALAZÓN AZORíN, J. M. (1977). Relativa a las presiones de los comerciantes.

87 Carta del conde de Montarco, 30-XI-1804, citada por PALAzón AzORÍN, J. M. (1977). En Diario de Alicante, 2/XII/1927, consta que el día 30 de noviembre sólo se registraron 5 enfermos y 2 fallecidos

88 JOVER, N.C. (1863), apéndice pp. 40, 41. Otros autores hacen referencia al mismo documento. 
TABLA 1: Estado general del 24 de diciembre de 1804

\begin{tabular}{|c|c|c|c|c|c|}
\hline & $\begin{array}{l}\text { INCONTA- } \\
\text { GIADOS }\end{array}$ & $\begin{array}{c}\text { ENFER- } \\
\text { MOS }\end{array}$ & CURADOS & Muertos & $\begin{array}{l}\text { EMIGRA- } \\
\text { DOS }\end{array}$ \\
\hline HOMBRES & 518 & 2.974 & 1.785 & 1.189 & 709 \\
\hline MUJERES & 791 & 3.868 & 3.061 & 807 & 948 \\
\hline PÁRVULOS & 829 & 1.755 & 1.589 & 166 & 377 \\
\hline CANÓNIGOS & 1 & 6 & 1 & 5 & 7 \\
\hline CURAS Y SUS TENIENTES & 1 & 9 & 2 & 7 & 2 \\
\hline CAPELLANES & 1 & 11 & 6 & 5 & 5 \\
\hline RELIGIOSOS & 35 & 66 & 38 & 28 & 44 \\
\hline MONJAS & 6 & 52 & 41 & 11 & - \\
\hline REGIDORES & - & 4 & 2 & 2 & 3 \\
\hline OFICIALES DEL REGIMIENTO DE AMÉRICA & 4 & 20 & 13 & 7 & - \\
\hline CAPELLANES DE IDEM & - & 2 & - & 2 & - \\
\hline CIRUJANOS DE IDEM & 2 & 1 & - & 1 & - \\
\hline MAESTRO ARMERO DE IDEM & 1 & 1 & - & 1 & - \\
\hline OFICIALES DE ARTILLERIA & 1 & 1 & - & 1 & - \\
\hline IDEM DE HÚSARES & - & 1 & - & 1 & - \\
\hline SOLDADOS DEL REGIMIENTO DE AMÉRICA & 176 & 496 & 324 & 172 & - \\
\hline IDEM DE ARTILLERIA & 1 & 12 & 5 & 7 & - \\
\hline IDEM DE HÚSARES & 1 & 20 & 16 & 4 & - \\
\hline ABOGADOS & - & 6 & 2 & 4 & 6 \\
\hline ESCRIBANOS & 1 & 17 & 10 & 7 & 5 \\
\hline EMPLEADOS DE RENTAS & 23 & 94 & 46 & 18 & 4 \\
\hline MÉDICOS & 3 & 10 & 6 & 4 & - \\
\hline EMPLEADOS DE LA REAL FÁBRICA DE CIGARROS & 4 & 3 & 3 & 1 & - \\
\hline CIRUJANOS & - & 14 & 7 & 7 & - \\
\hline BOTICARIOS & - & 16 & 7 & 9 & - \\
\hline RENTA DEL CORREO & - & 8 & 4 & 4 & - \\
\hline ESTADO MAYOR DE LA PLAZA & 2 & 4 & 2 & 2 & - \\
\hline REAL CUERPO DE INGENIEROS & 1 & - & - & - & - \\
\hline OFICIALES DE LA REAL ARMADA & 2 & 1 & 1 & - & - \\
\hline ID. DE MILICIAS DE CIUDAD-RODRIGO & - & 1 & 1 & - & - \\
\hline SUMA TOTAL & 2.404 & 9.443 & 6.971 & 2.472 & 2.110 \\
\hline
\end{tabular}

Personas del vecindario anterior al contagio

Al pie del documento consta: Se han substraído de las dos últimas sumas 745 individuos de la tropa inclusos en este estado.

(Hay un error en la columna de enfermos que suman realmente 9.473 y no 9.443.)

FUENTE: Jover, N. C. (1863), Apéndice pp. 40,41. Trascripción del «Estado general de los enfermos, curados y muertos del contagio que ha habido en esta ciudad y sus arrabales desde el día catorce de septiembre hasta el siete de diciembre del año de la fecha, con noticia de los que no lo han padecido, de los emigrados, vecindario anterior y actual; en que se distinguen hombres, mujeres, párvulos y las personas de algún destino particular». 
según los cuales sólo se contabilizaban ocho enfermos, de los que dos habían falleci$\mathrm{do}^{89}$. Las autoridades superiores demoraron la reanudación de la vida comercial en Alicante, a pesar de las razones esgrimidas por el gobernador, respaldándose en que aunque no existieran ya enfermos de fiebre amarilla la ciudad debía guardar una cuarentena prudencial ${ }^{90}$.

El médico Lorite era partidario de comenzar la fumigación general pero el 4 de diciembre la Junta Suprema de Sanidad ordenó mantener todas las precauciones y esperar la oportuna licencia para la desinfección, que debía recibirse del capitán general ${ }^{91}$. Desde Valencia, Domingo Izquierdo denegó la celebración del Te Deum y prohibió cualquier demostración pública religiosa. El 13 de diciembre la Junta Suprema de Sanidad pidió al médico Juan Manuel de Aréjula que enviase ejemplares del método que redactó —durante la epidemia de Málaga de 1800 — para «desinfeccionar a los pueblos que padeciesen la epidemia» a los médicos comisionados de los pueblos donde se hubiese padecido la fiebre amarilla ${ }^{92}$. Dichas instrucciones llegaron a Alicante 15 días después -el día $30^{93}$. Las fumigaciones con sustancias químicas comenzaron a emplearse a principios de siglo XIX. Tradicionalmente se utilizaban sustancias aromáticas que combatían o anulaban el mal olor, considerado productor de enfermedades. Aréjula combatía en sus memorias estas creencias arraigadas en la población ${ }^{94}$. Las fumigaciones mediante vapores de ácidos se justificaban por creerse que en las "putrefacciones», favorecidas por el calor y la humedad, se emitía hidrógeno y gas carbónico que se identificaban como los «miasmas» productores de «fiebres» que se neutralizaban con los primeros. Estas fumigaciones, cuya eficacia era discutida, se convirtieron en el instrumento con el que se pretendía devolver la confianza a la población, sin agravar el sistema económico, y además, con la autoridad de la ciencia, justificaban el retraso en la apertura de las comunicaciones de las poblaciones ${ }^{95}$. Esta practica fue apoyada por el gobierno, la Iglesia la divulgó entre las masas y las instituciones científicas la informaron favorablemente. El propio Godoy

\footnotetext{
${ }^{89}$ Carta del gobernador Betegón..., 1-XII-1804, citada por PALAZÓn AzoRín, J. M. (1977).

90 Diario de Alicante, 2/XII/1927.

91 Carta de la Junta Suprema de Sanidad..., 4-XII-1804, citada por PALAZÓN Azorín, J. M. (1977) y Diario de Alicante, 2/XII/1927.

92 Carta de la Junta Suprema de Sanidad..., 13-XII-1804, citada por PALAZÓn AzORín, J. M. (1977).

93 AMA. Sanidad, leg. 1, núm. 17, h.1. Carta a Juan Manuel de Aréjula, fechada en Alicante a 2 de enero de 1805. Dichas fumigaciones las dirigiría Ambrosio Lorite en Alicante.

Las fumigaciones se apoyaron en el avance de la Química. Morveau ideó la desinfección mediante los vapores de cloro, iniciando de esta forma la desinfección por sustancias químicas. En 1803, la imprenta real editó la traducción de la obra de Morveau, Tratado de los medios de desinfeccionar el ayre, precaver el contagio y detener sus progresos. Sus ideas para desinfectar objetos, datan de 1773, obedeciendo la traducción y difusión a las necesidades de frenar el avance de la fiebre amarilla.

94 Diario de Alicante, 16/XII/1927.

95 CARrillo, J. L. (1986), Juan Manuel de Aréjula (1755-1830) Estudio sobre la fiebre amarilla, Ministerio de Sanidad y Consumo, Madrid, pp. 21/22, 27-32.
} 
fue partidario de popularizarlas y apoyó gubernamentalmente experiencias destinadas a reforzar su eficacia, silenciando y reprimiendo las tendencias contrarias ${ }^{96}$.

Durante el mes de enero se agravó la situación de miseria y falta de caudales ${ }^{97}$. La Junta Suprema de Sanidad, delegó en el capitán general de Valencia la emisión de las órdenes sobre la desinfección previa a la apertura de la comunicación ${ }^{98}$. Aunque ya no había defunciones por fiebre amarilla las órdenes de Valencia no se habían recibido el 2 de enero de 1805 por lo que Betegón escribió impaciente a Domingo Izquierdo para comunicarle que comenzaba a preparar lo necesario para las fumigaciones, en espera de que mandara iniciarlas, obligado por las circunstancias en que se hallaba la ciudad ${ }^{99}$. Al día siguiente el gobernador de Alicante emitió unas instrucciones — previamente acordadas con la Junta de Sanidad municipal y apoyadas por órdenes del rey comunicadas por la Suprema Junta de Sanidad— para activar la «depuración» de la ciudad. Denunciaba haber avisado, en varias ocasiones, al capitán general del Reino, sin haber recibido respuesta, e insistía en las deplorables condiciones en que se hallaban los habitantes de la ciudad:

... procurando la Junta no retardar más tiempo la desinfección, ni mirar con indiferencia la aflicción y miseria del pueblo, más temible que el mismo contagio que ha experimentado, del que ya se ve libre por la misericordia de Dios; en virtud, pues, de dichas superiores ordenes (...) ha resuelto proceder inmediatamente a la desinfección y descontagio general, (...) se facilita alzar la incomunicación, tan interesante al vecindario, por las ventajas que le proporciona el comercio, la Real Fábrica de Cigarros y otros establecimientos que sostienen a este pueblo ${ }^{100}$

En estas instrucciones pedía a los vecinos que abrieran sus casas a los comisarios de la Junta y al médico Lorite, que dirigía la fumigación, y no ocultaran ningún efecto o ropa de los contagiados para que el expurgo se realizase con «toda prolixidad y exactitud». El día que se les señalase debían franquear sus casas, presentando los objetos a expurgar, y tener preparado fuego, una o dos cazuelas y un poco de azufre para no retardar esta operación. Si no poseían medios económicos, el diputado de barrio les proveería de lo necesario. Estas fumigaciones era preceptivo realizarlas en

\footnotetext{
96 Años después, el mismo Aréjula divulgó la ineficacia de las fumigaciones que tanta aceptación tuvieron en los primeros años del siglo XIX: ARÉJULA, M. de (1821), Memoria sobre la ninguna utilidad de uso de los gases ácidos para la desinfección o purificación de las materias contagiosas y de los contagios, Imprenta del Gobierno, Esparraguera, 26 p.

97 Sobre la diferente manera en que la población alicantina vivió la epidemia vid PASCUAL ARTIAGA, Mercedes (1998-99) «Las reacciones de la población alicantina ante la epidemia de fiebre amarilla de 1804», Revista de historia moderna, 17, pp: 167-192.

98 AMA. Sanidad, leg. 1, núm. 2. Carta del conde de Montarco al capitán general de Valencia, fechada en Madrid a 4 de enero de 1805.

99 AMA. Sanidad, leg. 1, núm. 17, h. 3. Carta de Betegón a Izquierdo, Alicante a 2 de enero de 1805.

100 AMA. Sanidad, sig.181. Alicante, 3 de enero de 1805. Instrucciones que deben seguirse para practicar las desinfecciones en las casas y fumigaciones de ropas.
} 
la ciudad, sus arrabales, embarcaciones del puerto y heredades del término. En los lugares donde ya se habían efectuado debían repetirse para mayor seguridad. El día 4 de enero Domingo Izquierdo comunicó el nombramiento del ingeniero Manuel Mirallas —que residió en Elche- que seguiría las órdenes emitidas desde Valencia, reconocería toda la huerta y proporcionaría el material necesario para realizarlas, ajustándose a las instrucciones del médico Aréjula y bajo la dirección de don Ambrosio Lorite $^{101}$. El 5 de enero Betegón escribió al conde de Montarco, a Godoy y a varios ministros informándoles de haber publicado un bando ordenando comenzar la fumigación esa misma tarde, ya que era apremiante la apertura del puerto y de la fábrica de cigarros para paliar las condiciones de miseria de la población ${ }^{102}$. El 6 de enero - sin haber recibido noticias del capitán general de Valencia- el gobernador reclamó nuevamente que se diera la orden de iniciar las operaciones de expurgo y le informó de su comienzo, en los mismos términos en que lo había hecho al conde de Montarco ${ }^{103}$. Domingo Izquierdo le contestó, el 8 de enero, insistiendo en la rigurosidad con que debían realizarse las fumigaciones:

...las fumigaciones se hagan con la devida exactitud, que sean extensivas a los muebles y efectos que por este medio pueden quedar purificados; que se cepillen y pinten las puertas y ventanas de los quartos en donde huviese havido algún enfermo o muerto contagiado de la fiebre $(. .$.$) no obstante las dudas, acerca de si el áccido sulfúrico neutraliza o no el virus de$ la fiebre, entiendo de la mayor importancia (...) para que no nos quede el rezelo, de que nuestra omición ha producido daño 104

Izquierdo no podría enviar sus «providencias» para la apertura de la comunicación - $\tan$ ansiada por el gobernador de Alicante — hasta que no se completara la fumigación. Unos días después Izquierdo le recordaba, y también a los vocales de la Junta de Sanidad de Alicante, que después de las fumigaciones debían guardarse cuarentenas preventivas de entre 10 y 30 días según las circunstancias del pueblo contagiado ${ }^{105}$.

El encargado de las fumigaciones en la huerta de Alicante fue el ingeniero Manuel Mirallas que iba acompañado de un escribano, unos médicos y un capitán de

101 AMA. Sanidad, leg. 1, núm. 2, h.7. Carta de Domingo Izquierdo al gobernador Betegón, fechada en Valencia a 4 de enero de 1805.

102 AMA. Sanidad, leg. 1, núm. 17, h.4. Carta del gobernador Betegón a Godoy y a los sres. Miguel Cayetano Soler, Pedro Ceballos y José Antonio Caballero, comunicándoles el buen estado de salud de la población, la inminente desinfección general y la urgente apertura del puerto y de la fábrica de cigarros.

103 AMA. Sanidad, leg. 1, núm. 17, h. 5. Carta de Betegón a Izquierdo, Alicante 6 de enero de 1805.

104 AMA. Sanidad, leg. 1, núm. 2, h. 6. Carta de Izquierdo a Betegón, Valencia 8 de enero de 1805.

105 AMA. Sanidad, leg. 1, núm. 2, h. 5. Carta de Izquierdo a Betegón, Valencia a 11 de enero de 1805. Domingo Izquierdo aludía al deseo del gobernador de Alicante de abrir la comunicación del campo y de la ciudad, al mismo tiempo. Para justificar su petición, había enviado un certificado firmado por diez médicos que acreditaban que la ciudad se encontraba en el mejor estado de salud. Sin embargo, el deseo de Betegón no podía satisfacerse ya que no habían concluido las fumigaciones en la ciudad. 
húsares. Concluidas las mismas, el territorio se declaraba sano pero seguía acordonado para impedir la comunicación con las zonas no expurgadas. Diariamente, en los remates del cordón del «país sano», se reunían los encargados del expurgo con los «profesores» de Alicante para informarse del estado de salud de los habitantes ${ }^{106}$. El comisionado de Alicante, José Rodríguez, acudía al lugar que indicaba Mirallas para señalar los nuevos puntos del cordón, conforme se iban declarando sanos los territorios, y marcaba los sitios más a propósito para celebrar los mercados ${ }^{107}$. Durante el mes de enero continuaron estas operaciones y el día 22 sólo quedaban por declarar sanos la ciudad de Alicante, el pueblo de Peñacerrada, San Juan y Benimaclet, que estaban en observación ${ }^{108}$. Este mismo día, Pedro de Buck y O’Donell escribió a Betegón citándole junto con Manuel Mirallas —en la casa de Vicente Llácer cerca del «Portichuelo»— a las 9 de la mañana del día 25 para fijar las reglas y detalles que permitieran abrir el día 26 de enero la comunicación, el puerto y la fábrica de cigarros $^{109}$. El día 26 acudirían así mismo los médicos, un escribano y los oficiales que habían realizado los reconocimientos junto con los «profesores» que realizaron el expurgo de San Juan, Benimagrell y Peñacerrada. Se recomendaba la asistencia de todos los médicos de la plaza de Alicante junto con el director de la epidemia ${ }^{110}$.

Previamente a la apertura de la comunicación, el gobernador alicantino escribió a Izquierdo y le expuso el mal estado en que se encontraba la ciudad y la falta de fondos para remediarlo:

Las calles no están empedradas, el matadero está en medio de la ciudad y los conductos de las aguas y de las inmundicias son defectuosos, que uno y otro influye y perjudica mucho la salud (...) y lo que únicamente encuentro [que] podrá tener pronto remedio es el de dar libre salida al mar a las inmundicias, si d. Manuel Mirallas quiere atender a la parte de la obra que le pertenece, en lo que está a su cargo, de este muelle111

Era preciso combatir la falta de higiene con medidas de policía en la ciudad, para evitar un nuevo rebrote de la enfermedad. De esta forma el gobernador eludía la responsabilidad en caso de que la enfermedad se reprodujese.

El 26 de enero de 1805 Domingo Izquierdo se encargó de difundir que se había autorizado la apertura de la comunicación con Alicante y su puerto ${ }^{112}$.

106 AMA. Sanidad, leg. 1, núm. 2. Carta de Mirallas a Betegón, Villafranqueza, 12 y 13 de enero de 1805. Anotación de Mirallas a Betegón. Muchamiel, 16 de enero de 1805.

107 AMA. Sanidad, leg. 1, núm. 2. Carta de Betegón a Mirallas, Alicante, 16 de enero de 1805; núm. 18 Carta de Mirallas a Betegón, Villafranqueza 13 de enero de 1805.

108 AMA. Sanidad, leg. 1, núm. 2. Carta de Mirallas a Betegón, Villafranqueza, 22 de enero de 1805.

109 AMA. Sanidad, leg. 1, núm. 2, h. 34, 35. Carta de Pedro Buck a Betegón, Elche, 22 de enero de 1805.

110 AMA. Sanidad, leg. 1, núm. 2. Cartas de Mirallas a Betegón. 23 y 24 de enero de 1805.

111 AMA. Sanidad, leg. 1, núm. 17. Carta de Betegón a Izquierdo, Alicante, 24 de enero de 1805.

112 AHO. FM. D. 1240, núm. 40. Carta de Izquierdo al gobernador de Orihuela, fechada en el Real de Valencia a 25 de enero de 1805. 


\section{PRECAUCIONES tOMAdAS POR LAS AUTORIDADES ALICANTINAS EN 1805 PARA EVITAR UNA NUEVA EPIDEMIA DE FIEBRE AMARILLA}

En junio de 1805 - temiéndose que con la llegada del verano apareciera de nuevo la epidemia - comenzaron a adoptarse las medidas oportunas ${ }^{113}$.

Una de las primeras actuaciones — anunciada mediante edictos en mayo de 1805 y promovida por la fe de la población en la Santa Faz - fue la de trasladar la reliquia a la colegial de San Nicolás, cuando concluyera la desinfección general ${ }^{114}$, que permaneció en la ciudad hasta pasado el mes de octubre ${ }^{115}$.

A comienzos de junio de 1805, el gobernador de Alicante dictó una serie de precauciones para evitar que las personas susceptibles a la fiebre amarilla pernoctasen en la ciudad, permitiéndoseles — siempre que la ciudad permaneciese sana- entrar y salir. Los individuos que fueran inmunes - por haber pasado la enfermedad o haber residido más de un año en las Antillas o en la costa firme - debían tramitar un certificado emitido por personas fidedignas, por las respectivas Juntas de Sanidad o por los facultativos que les hubieran atendido. Los jornaleros, artesanos, artistas o sirvientes que se hubieran establecido en Alicante después del día 26 de enero de 1805, día en que se abrió la comunicación de la ciudad, debían regresar al pueblo donde residían con anterioridad. Estas normas debían cumplirse antes del día 15 de junio. Se ordenó el aseo y limpieza de las casas y calles. Debían lavarse las puertas y blanquear las paredes, hasta la altura que hubieran podido rozar los contagiados por la epidemia ${ }^{116}$.

Guardas de sanidad controlarían el paso de las personas a través de las puertas de la ciudad. Mientras durase el riesgo de un rebrote, se prohibía la celebración de las ferias por ser lugares de fácil introducción y venta de géneros y efectos sospechosos. Cada semana se fumigarían los lugares donde se acumulasen las personas para eliminar los «vapores» que pudieran perjudicar la salubridad del aire.

A principios de julio de 1805, el Consejo Supremo envió una circular, extracto de la Real Orden del 18 de junio, para el control del «pase de las personas y efectos procedentes de los pueblos que han padecido el contagio en el año próximo pasado» ${ }^{117}$. Se proporcionaban instrucciones sobre las características que debían reunir los pasaportes de sanidad y las normas que las justicias y los jefes de los cordones

113 AMA. Sanidad, leg. 1, núm. 24. Extracto de las providencias tomadas por la Sanidad de Liorna. Liorna sufrió la fiebre amarilla en 1804. No indica el año pero comienzan en el día 3 de octubre y concluyen el 19 de diciembre, por lo que probablemente se recibieron en Alicante concluida la epidemia de 1804.

114 AMA. Libro de cabildos de 1805, arm. 9, lib. 100, f. 99 v. Sesión ordinaria del 10 de mayo de 1805.

115 AMA. Libro de cabildos de 1805, f. 159. Sesión extraordinaria del 24 de septiembre de 1805.

116 AMA. Sanidad, leg. 1, núm. 19. Bando del gobernador Betegón en el que se toman precauciones, Alicante a 8 de junio de 1805; , sig. 182. Edicto de José Betegón. Fechado en Alicante a 17 de junio de 1805. Prevenciones a tomar ante la proximidad del verano con motivo de un posible rebrote de fiebre amarilla

117 AMA. Sanidad, leg. 1, núm. 7, h. 2. Madrid, 5 de julio de 1805, Circular con órdenes de S.M. comunicadas en 18 de junio por José Antonio Caballero. 
sanitarios debían observar para su admisión. Estas medidas debían estar vigentes hasta finales de septiembre. Los capitanes o comandantes generales eran los responsables de los efectos retenidos y debían custodiarlos y «evitar su extravío». Otras medidas regulaban las cuarentenas, y su duración, de los equipajes o efectos de las embarcaciones que arribasen a los puertos ${ }^{118}$.

Las medidas preventivas se mantuvieron durante todo el verano y el 8 de octubre de 1805 en la sesión del cabildo municipal ${ }^{119}$ el gobernador, como presidente de la Junta de Sanidad, difundía una Real Orden en la que anunciaba el levantamiento de los cordones y el fin de las cuarentenas pudiendo dejarse libre la comunicación por lo perjudiciales que resultaban estas trabas al comercio ${ }^{120}$.

Como acción de gracias al «Todo poderoso» se realizaría un Te Deum los días 20, 21 y 22 de octubre, en el que estaría presente la Santísima Faz, a cuyo acto asistirían ambos cabildos, el clero, las comunidades y gremios, junto con el pueblo alicantino. Se llamaba a la generosidad a los vecinos más pudientes de la población con el objeto de aliviar la miseria de sus conciudadanos. Se recordaba que todo fuego artificial, cohetes o truenos estaba prohibido — como se había reiterado en las correspondientes reales cédulas y órdenes recientes_ castigándose con rigurosas penas.

\section{CONCLUSIÓN}

Las medidas preventivas destinadas a evitar que otros territorios se contagiasen emanaba de las autoridades centrales o provinciales, que supervisaban las medidas que se adoptaban para solucionar los problemas locales mediante los llamados Directores de epidemias. Desde fuera del municipio el interés versaba en controlar que la epidemia no rebasara el cordón sanitario. La labor encaminada a solucionar los problemas que la declaración de la epidemia provocaba entre los habitantes recayó en las autoridades alicantinas. La financiación de los gastos ocasionados durante la misma a causa de las diferentes medidas adoptadas, que incluía la manutención de los indigentes de la ciudad, fue controvertida al carecerse de un fondo destinado a tal efecto.

La forma de organización de las propias Juntas de Sanidad, reveló su ineficacia en cuanto a la rapidez y efectividad de las medidas tomadas. Posiblemente la Junta Provincial cumplió a la perfección su papel que parece que fue retardar al máximo la apertura de la comunicación de la ciudad de Alicante para evitar el riesgo de otras poblaciones a importar la enfermedad. Esto parece si atendemos al largo período de tiempo que transcurrió desde el 25 de diciembre en que ya no había ni enfermos ni

118 Ibidem.

119 AMA. Libro de cabildos de 1805, f. 165 v. Cabildo extraordinario del 8 de octubre de 1805.

120 AMA. Sanidad, leg. 1, núm. 22. Bando de Betegón, comunicando la Real Orden del 26 de septiembre de 1805, sobre eliminación de cordones y la celebración del Te Deum. Alicante 7 de octubre de 1805. 
muertos de fiebre amarilla hasta el 26 de enero, día en el que se anunció el fin del aislamiento. La misma razón pareció existir en el retraso por parte del capitán general de Valencia a enviar las órdenes pertinentes para el comienzo de las obligatorias fumigaciones hasta que Betegón tomó la iniciativa tras insistir en numerosas ocasiones debido a la miseria en que se hallaba la población y el esfuerzo económico que suponía mantener a todos los indigentes.

En cuanto a la influencia en las medidas adoptadas en estas epidemias por la medicina del momento o por la vida social o económica. Los comerciantes elevaron sus protestas por los perjuicios que se les ocasionaban con este tipo de actuaciones pero no fueron demasiado atendidos. Lo extremado del aislamiento en casos de epidemia provocó a principios de siglo XIX que se ocultase sistemáticamente los primeros casos de estas enfermedades por las pérdidas económicas para el conjunto de la población, no solo para los comerciantes o burgueses. Más que la medicina del momento, fueron los médicos cercanos al rey y sus ministros los que influyeron decisivamente en imponer su opinión en las medidas a adoptar. En esta epidemia de fiebre amarilla de 1804, en Alicante se reciben frecuentemente las tendencias de dos médicos: Juan Manuel Aréjula en cuanto a las fumigaciones previas a la conclusión del aislamiento, que parece que fueron utilizadas, como revela Carrillo, como excusa para prolongar el plazo de seguridad del aislamiento, además de presentarlo como experto conocedor de la nueva enfermedad al tener experiencias previas vividas en Andalucía. El otro médico que impuso su opinión sobre la naturaleza de la enfermedad y la forma de combatirla fue Tadeo de la Fuente. Un dictamen suyo de octubre de 1804 imponía su postura de lo que había que hacer en caso de que en una casa murieran dos o tres en pocos días:

No hay que cansarse: no dexará de correr la sangre humana derramada sin piedad por la vana confianza y por las pasiones, disputas eternas y diversidad de pareceres e intereses de los hombres, mientras no se establezca, por canon médico político, que no por conocimientos positivos, que en tales casos (...) están autorizados los pueblos a empezar preventivamente sus defensas y sus precauciones y a seguirlas con tenacidad (...)Una sola providencia sencilla y practicable bastava seguramente para aniquilar todo este caos inmenso de impedimentos, de controversias, de miseria y de desorden.

Mándese con la mayor severidad que se aísle inmediatamente una casa qualquiera en que un mal, sea el que fuere, haya ido recorriendo toda la mayor parte de la familia y produciendo dos o tres muertos en pocos días (...) y no se apoderará jamás del distrito ninguno de estos infinitos contagios puros que devoran la población de quando en quando, por más que la casualidad, el descuido, la improvisión, los intereses particulares, ni otra qualquiera causa siga trabajando por introducirnos en nuestro territorio estos regalos de la muerte y estos comercios de sangre. Prohíbase, del modo más firme y terminante, hacer caso alguno de las disputas ordinarias sobre nombres vagos y pestíferas cantilenas de fiebres pútridas, malignas, estacionales biliosas, no epidémicas, locales y otras de este jaez, que haciendo perder un tiempo fugaz y preciosísimo y siendo únicamente producidas por la ignorancia o por las pasiones, solo sirven para alucinarnos mutuamente y hacer más destrozos que la misma peste. Hágase responsables hasta el último extremo a los facultativos, a los magistrados mismos y a 


\section{LA CIUDAD ANTE EL CONTAGIO: MEDIDAS POLÍTICAS Y ADMINISTRATIVAS}

las Juntas de Sanidad que hayan omitido las referidas precauciones con una casa qualquiera que se hayan verificado las dos circunstancias sobredichas ${ }^{121}$

Este documento refleja la postura que debía adoptarse y que emanaba de todas las disposiciones procedentes de las instrucciones de las Juntas Suprema y Provincial de Sanidad, culpando directamente a los médicos y autoridades y a la misma Junta local de sanidad de cualquier desviación en este sentido y de las consecuencias negativas que la imposibilidad de controlar la epidemia produjese. El centralismo imperante impedía otros foros para polemizar sobre esta postura, polémicas que surgieron más tarde sobre todo en las epidemias coléricas.

\section{GRÁFICA 1}

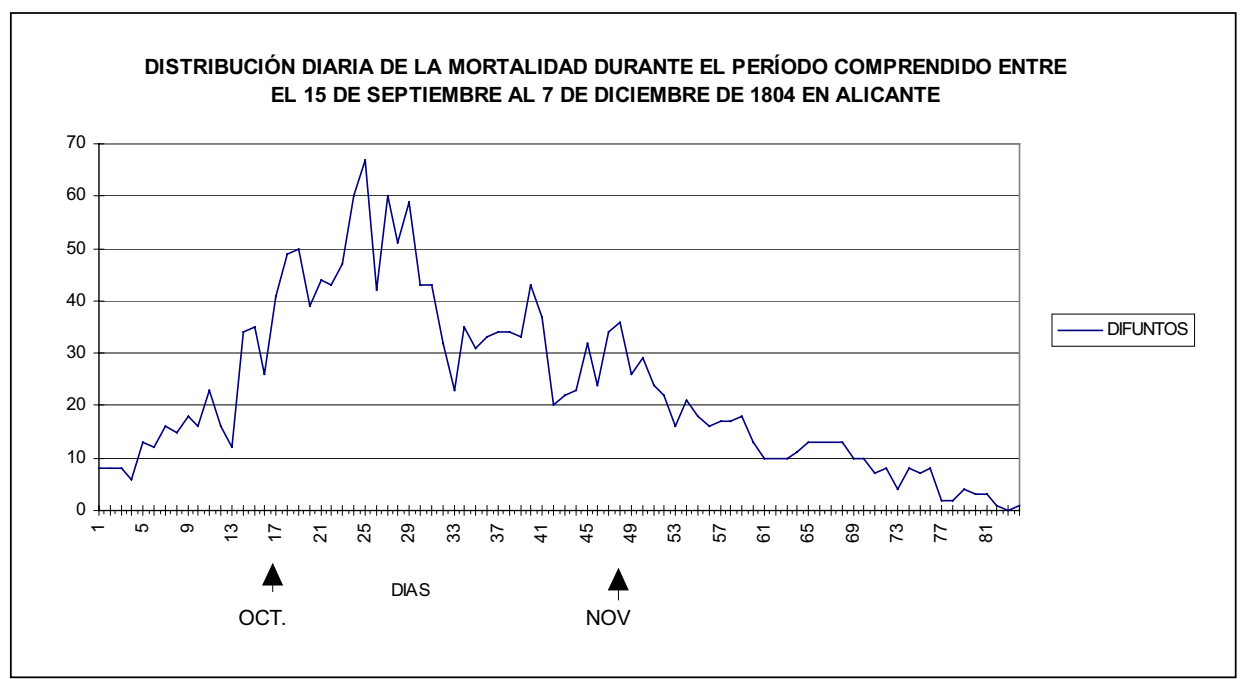

FUENTE: PALAZÓN AZORÍN, J. M., (1977), op. cit., en los «Partes diarios de médicos y hospitales, 15-XII$1804 »$ y «Muertos que resultan en esta población, 10-XII-1804». Elaboración propia.

121 AMA. Sanidad, arm. 19, leg. 65, núm. 20. 